\title{
Coalition-Committees as Network Interventions: Baseline Network Composition in Context of Childhood Obesity Prevention Interventions
}

\author{
Travis R. Moore ${ }^{1}$, Mark C. Pachucki ${ }^{2}$, Larissa Calancie ${ }^{1}$, Ariella R. Korn ${ }^{3}$, Erin Hennessy ${ }^{1}$ \\ and Christina D. Economos 1,*
}

check for updates

Citation: Moore, T.R.; Pachucki, M.C.; Calancie, L.; Korn, A.R.; Hennessy, E.; Economos, C.D. Coalition-Committees as Network Interventions: Baseline Network Composition in Context of Childhood Obesity Prevention Interventions. Systems 2021, 9, 66. https://doi.org/ 10.3390 /systems 9030066

Academic Editors: Leandro Garcia, Ruth Hunter and Jason Thompson

Received: 30 July 2021

Accepted: 30 August 2021

Published: 3 September 2021

Publisher's Note: MDPI stays neutral with regard to jurisdictional claims in published maps and institutional affiliations.

Copyright: (c) 2021 by the authors. Licensee MDPI, Basel, Switzerland. This article is an open access article distributed under the terms and conditions of the Creative Commons Attribution (CC BY) license (https:/ / creativecommons.org/licenses/by/ $4.0 /)$.
1 ChildObesity180, Friedman School of Nutrition Science and Policy, Tufts University, 150 Harrison Ave Boston, MA 02111, USA; travis.moore@tufts.edu (T.R.M.); larissa.calancie@tufts.edu (L.C.); erin.hennessy@tufts.edu (E.H.)

2 Department of Sociology, Computational Social Science Institute, University of Massachusetts Amherst, Amherst, MA 01003, USA; mpachucki@umass.edu

3 Cancer Prevention Fellowship Program, Implementation Science, Office of the Director, Division of Cancer Control and Population Sciences, National Cancer Institute, Bethesda, MD 20892, USA; ariella.korn@nih.gov

* Correspondence: christina.economos@tufts.edu; Tel.: +1-617-636-3784

\begin{abstract}
Community coalitions can address local issues with deep, historic, and contextual understanding that enables customized implementation of evidence-based strategies. The individuals within the coalition, their partnerships, and the social context is likely an important component of unraveling the challenges of implementation so interventions reach people in need. We focus on the relevance of baseline coalition-committee network (CCN), the networks of purposely formed subcommittees within community coalitions, structure as one of the moderating, theoretical links between community coalition social networks and intervention success. We explore the baseline composition and characteristics of five CCNs at the beginning of childhood obesity prevention interventions. Using a combination of social network, multidimensional scaling, and correspondence analyses, we examine the structure and heterogeneity of five CCNs, each consisting of a core group of stakeholders in the coalition and sometimes the broader community itself. Cross-sectional analyses are used to examine the composition of coalition-committees related to network density, centralization, hierarchy, and coalition demographics and characteristics. Results indicate that CCNs are patterned in their structure and characteristics, and we discuss whether adjustments to childhood obesity prevention interventions according to baseline structure and characteristics could be advantageous for intervention implementation. Together, these findings can inform future longitudinal investigations into CCN network structure.
\end{abstract}

Keywords: coalitions; network intervention; social network analysis; obesity prevention; community development

\section{Introduction}

Community coalitions are a common strategy for addressing entrenched social and health issues at a local level [1,2]. These multi-sector collaborations are often embedded in complex systems of intervention, defined as a collection of locally tailored, structured programs or practices implemented by an array of stakeholders, that shape the way these systems form, develop, and function [3]. In turn, they have the potential to influence the trajectories of those systems. Community Coalition Action Theory (CCAT) suggests that one important way coalitions influence system-level change is building coalition membership for greater capacity to effect community-level change [4]. In particular, community coalitions create a context for organizations to develop networks that go beyond the scope and time frame of coalition activity, potentially creating enduring effects on both the capacity of individual organizations and the system as a whole $[5,6]$. 
Childhood obesity, defined by a population-specific body mass index percentile of 95\% or greater, impacts almost $20 \%$ of the U.S. population, with $13.4 \%$ prevalence among 2 - to 5-year-olds and $20.3 \%$ prevalence among 6- to 11-year-olds [7]. Worldwide, the prevalence of overweight and obesity among children and adolescents ages 5-19 is over 20\% [8]. Community coalitions that focus on preventing childhood obesity intervene in the upstream (e.g., choosing evidence-based strategies) and midstream (e.g., implementing policy and practice strategies) to impact downstream or proximal health outcomes [9]. Such coalitions have seen varying degrees of success in implementing substantive and sustainable policy, practice, and environmental (PPE) strategies for community-wide systems change [10-13]. Coalitions focused on childhood health promotion have effectively shifted informal policies within organizations (e.g., hospitals and schools) and formal policies via local and state legislation, which includes generating support in the government and private sector for sustainable health systems change [14-17]. They have also affected environmental changes in local neighborhoods by, for example, supporting the creation, rehabilitation, and maintenance of parks, playgrounds, and recreation facilities in underserved residential areas $[14,16,18-20]$. Even coalitions that have not successfully created positive changes in PPEs [21-23] have, via community organizing, improved upstream health determinants by supporting infrastructures of social services, capacity building, sense of community, and synergistic efforts to increase the flow of information, expertise, and resources [24]. Such systemic changes have reinforcing effects in shifting broad behavioral norms through social diffusion across populations $[25,26]$. Such community-wide changes can be observed years after implementation of coalition PPE-change strategies, and are thus key components of reducing chronic disease morbidity and mortality and increasing the quality of life $[14,18,27-29]$.

While the benefits of community coalitions are becoming clearer [30], a dearth of research around coalition-committee networks (CCN) that are embedded within coalitions remains. In our research, CCNs are small groups of multi-sector stakeholders who were either drawn from a single coalition, multiple coalitions, or a coalition and additional invited community members. Similar to community coalitions, more research is needed on CCNs to: (1) determine the optimal structure of CCNs that are tailored to local contexts (e.g., collaborative history, culture, demographics); and (2) understand the optimal collaborative behavior of CCNs that drive diffusion and implementation of evidence-based interventions for childhood obesity prevention. One issue contributing to this gap in research is the use of in-depth case studies. Some researchers use case studies of one, though sometimes multiple, community coalitions within a single community to uncover the nuances of specific coalition action and broader intervention system impact [31-33]. These case studies, however, generally do not focus on smaller sub-groups of multi-sector stakeholders. While in-depth case studies that provide insight into the composition of specific community coalitions exist [34], little research has been conducted on understanding the structure of smaller working groups of multi-sector stakeholders that are drawn from community coalitions across multiple geographies. Focusing on a single community coalition limits the ability to generalize childhood obesity prevention strategies to other communities. The structure of social networks (e.g., size, density, interconnectedness among members) is hypothesized to shape health behavior and attitudes [35]. Thus, more research that is grounded in CCAT and that describes the composition of CCNs across communities is needed [4].

In this article, we examined CCN composition because studies suggest that multisector partnerships may impact implementation of childhood obesity prevention interventions [36,37]. This is especially true when the intervention is geared to infuse evidencebased programs into practice [37]. As Valente and colleagues [37] describe, there are three social processes that are relevant and necessary in getting programs adopted, implemented, and sustained. First, Valente describes that partnerships are theorized to be vital to the successful adoption, implementation, and sustainability of interventions [38]. Second, for those who deliver the intervention, research has shown that interventions implemented 
by community-identified leaders are often more effective than those by non-leaders [39]. That is, interventions delivered by people from the community of the beneficiaries of the intervention will be more effective that those delivered by outside agencies that are less connected to intervention recipients. Third and finally, studies have shown that intervention effects may vary as a function of the recipients' social networks. For example, Shin and colleagues [40] demonstrated that children with friends who were physically inactive gained more from an obesity prevention intervention than those with physically active friends.

In order to examine composition, we conceptualize CCNs as networks that act to intervene in childhood health policies, practices, and environments and who are embedded either within larger coalitions or larger networks of individuals working to address drivers and consequences of childhood obesity in their communities [41]. These CCNs are generally embedded within community coalitions. Though there is expansive variation in the nature and function of coalitions, coalition networks [42] in public health [26,43-46] are known to be an intentional, structural, collective strategy that can (1) increase the flow of information across organizations [47-50]; (2) increase policy diffusion into practice [51]; (3) translate research evidence into action [52]; (4) create sustainable changes in health outcomes [21,53,54]; (5) make new partnerships and increase access to financial resources [55-57]; and (6) increase relationship strength and capacity [58,59]. Viewing coalition-committees as networks of individuals or organizations may aid in the study of the structure and dynamics that give rise to optimal coalition-committee formations, which may in turn lead to better implementation of chronic disease prevention PPE strategies. For example, using network metrics (of, e.g., network density [60], centralization [61], and clustering [62]) that describe the composition of coalition-committees as a function of a coalition's diverse set of organizations and organizational connections provides information on (1) the composition of coalition-committees that promotes or hinders formation and growth; (2) the collaboration types and partnership dynamics that exist among and within organizations in CCNs $[63,64]$; and (3) the structural patterns across coalition-committees.

The coalition-committees we partnered with in this article participated in the Stakeholder-driven Community Diffusion (SDCD) theory-informed childhood obesity prevention intervention $[9,34]$. The SDCD theory describes hypothesized causal mechanisms by a group of convened stakeholders can influence important child health goals in their community, such as promoting healthy weights among children and reduce health disparities [9]. The theory-informed intervention encompasses a four-part process hypothesized to result in the diffusion of knowledge, engagement, and research evidence use around child health through social network connections, into the organizations of the stakeholders who participate in the intervention and into the individuals and organizations who interact with intervention participants. The resulting diffusion is hypothesized to increase the prioritization of child health initiatives among community decision-makers and organizations. This increase is believed to catalyze and reinforce important policy, practice, and environmental improvements at the community level, with the goal of improving child health outcomes at the individual level.

In the five CCNs included in this study, we explore network structural features in association with key CCN (e.g., issue focus) and community (e.g., gender, age, education level) characteristics. The aim of this article is to compare the structure and characteristics of CCNs participating in a childhood obesity prevention intervention to (1) point to specific differences in coalition-committees and communities in which they are imbedded and (2) to underline the characteristics within coalition-committees and their broader system that may shape the implementation of childhood health interventions. We find that CCNs participating in our intervention have variation in their network structure and coalition characteristics that may differentially inform future childhood obesity prevention interventions. 


\section{Research Questions and Hypotheses}

This research conceptualizes coalition-committees as active intervention networks that diffuse evidence-based PPE strategies into the larger coalition and community systems in which they are imbedded. It explores the structure and composition of these networks in the context of a childhood obesity prevention intervention. Using social network analysis, multidimensional scaling analysis, and multiple correspondence analysis, it investigates the structure and composition of $\mathrm{CNNs}$, comparing within and across communities to assess patterns that may affect intervention implementation. The study examines crosssectional structure in each CCN of the following network properties: network density (the portion of potential connections in a network that are actual connections), degree centralization (or the overall cohesion of the network), and degree and sector assortativity, or the preference for individuals to connect with other individuals who are similar to them by demographics or sector. For these network properties, differences between the $\mathrm{CCNs}$ (coalition-committee plus first-degree alters; Network A), formed coalition-committees only (Network B), and coalition-committee first-degree alters only (Network C), are explored. We focus on three aspects of CNNs: coalition-committees, multi-sector representation, and demographic heterogeneity.

\subsection{Coalition-Committees}

Community coalitions frequently form coalition-committees of key decision makers, health champions, local health leaders, and, often, community members [30]. These coalition-committees, also known as teams, taskforces, working groups, and subcommittees, tend to be microcosms of the larger coalition, joined together by a common interest or cause, providing infrastructure that can be used to delegate responsibilities as well as coordinating service delivery $[65,66]$. Coalition-committees that focus on childhood obesity prevention or, more broadly, childhood health promotion, tend to meet to discuss strategic planning and make decisions that then diffuse to the broader coalition, ideally catalyzing organized, collective action to improve childhood health outcomes $[30,67]$. Coalition-committees also often form around specific projects or actions and may dissolve once those are completed. In our intervention [9], we assemble coalition-committees that are viewed as an intentional cluster of decision-makers, professionals, and community members (Network B) nested within the broader CCN (Network A), usually selected based on existing social networks of individuals working to promote childhood health within a coalition, their role within an organization whose activities are related to childhood obesity, direct or indirect lived experience with the factors influencing childhood obesity in their community, and based on capacity (e.g., time, funding) to participate. While committee function is frequently described in research literature, little is known about the structure of CCNs in context of a childhood obesity prevention intervention. However, based on our previous research $[9,34,68,69]$, we know that density and degree centralization start relatively high in both coalition-committees and their respective coalitions. Thus, we extend that research to include (a) five additional CCNs and (b) degree assortativity to test the following hypotheses:

Hypothesis 1 (H1). CCNs that were drawn from existing coalitions will demonstrate higher levels of density, degree centralization, and degree assortativity than the CCNs that were not drawn from existing coalitions.

\subsection{Sectors}

Multi-sector collaborations bring historically siloed sectors together to build capacity and solve complex systems issues. In childhood obesity prevention, the early childhood and healthcare sectors generally make up most of the sector representation in community coalitions working to improve child health outcomes. Research has shown that diversifying sector representation in community coalitions is crucial for generating unique perspectives on complex issues as well as increasing the capacity of the coalition to mobilize 
whole-of-community interventions [34]. However, little research exists on the status of sector representation in CCNs, particularly among members who are the most connected (i.e., have the highest number of relationships with other coalition members). Thus, this study examines sector heterogeneity across each CCN as well as among highly connected individuals within the CCN. The following hypotheses are tested:

Hypothesis 2 (H2). CCNs will display sector heterogeneity and nominal (sector) assortativity.

\subsection{Community-Coalition Networks and Community Characteristics}

A review of the literature indicates that childhood obesity prevention coalitions committees boast substantial diversity in their structure, behavior, size, sector representation, and level of community involvement $[30,70]$. One would expect similar diversity in CCNs, though evidence to support that is lacking. More research is needed comparing community coalitions and CCNs, aiming to identify common patterns across discrete groups and contexts. Thus, this study (1) compares CCNs to one another based on coalition-committee size, coalition-committee membership (i.e., director, programmatic, or a combination of the two), whether the coalition-committee was generated from an existing coalition or newly formed, meeting frequency, and focus (e.g., health equity and/or WIC); and (2) compares $\mathrm{CCNs}$ to one another based on their dissimilarity to their respective geographic community. The following hypotheses are tested:

Hypothesis 3 (H3). Obesity prevention coalition-committees across participating communities will be similar based on a set of CCN characteristics including coalition-committee size, frequency in meeting, and focus.

Hypothesis 4A (H4A). Based on our and others' previous research [2,3,71], CCNs will be disproportionately female, white, and hold a bachelor's degree or higher when compared to the community they serve.

Hypothesis 4B (H4B). CCNs will cluster based on their coalition-community dissimilarity.

\section{Methods}

This research is part of an ongoing initiative called Catalyzing Communities funded by the JPB Foundation to support the research and development of the SDCD theory, to study the way communities across the country work together to reverse the trends that drive childhood health disparities.

\subsection{Sample}

As seen in Table 1, the project currently works within five communities which we refer to as communities 1 through 5 to maintain anonymity. In each of the communities, we worked closely with two changemakers who were identified through existing partnerships and who helped identify the individuals who should be in each coalition-committee. The changemakers identified approximately 15 stakeholders to engage in the SDCD-informed intervention process (see [9] for a description of the intervention). These stakeholders formed the coalition-committees that participated in the intervention. The number of stakeholders in each coalition-committee differs based on the initial conversations with changemakers concerning who should be involved in strategic planning; and the capacity of coalition-committee members to participate in the intervention. A main consideration was inviting coalition-committee members who represented multiple sectors in the community. Coalition-committees focused on children, with some focusing on all children $0-18$ years old and others focusing on early childhood. While each coalition-committee focused on childhood health, their specific focus area varied, including childhood obesity prevention, health equity, healthcare access, and food insecurity. The community in which each coalition is imbedded tended to vary widely in population size, land area, race/ethnicity, education, and gender (Table 1). 
Table 1. Summary of community and coalition-committee characteristics [72].

\begin{tabular}{|c|c|c|c|c|c|}
\hline Community & 1 & 2 & 3 & 4 & 5 \\
\hline \multicolumn{6}{|l|}{$\begin{array}{l}\text { Community characteristics } \\
\text { (2019) }\end{array}$} \\
\hline Population estimate & 514,213 & 46,655 & 385,282 & 541,482 & 594,548 \\
\hline Land area $\left(\mathrm{mi}^{2}\right)$ & 785.0 & 4.8 & 82.5 & 226.7 & 96.8 \\
\hline $\begin{array}{l}\text { Median household income } \\
\text { (USD) }\end{array}$ & $\$ 53,739$ & $\$ 48,704$ & $\$ 20,407$ & $\$ 24,102$ & $\$ 25,266$ \\
\hline Foreign born $(\%)$ & 7.9 & 50.4 & 5.9 & 15.3 & 5.0 \\
\hline \multicolumn{6}{|l|}{ Race and ethnicity (\%) } \\
\hline Hispanic or Latino (all races) & 8.8 & 57.4 & 11.9 & 33.6 & 19.2 \\
\hline NH White & 69.0 & 32.6 & 40.0 & 62.1 & 44.8 \\
\hline NH Black or African American & 18.0 & 2.6 & 48.8 & 5.2 & 38.4 \\
\hline $\begin{array}{c}\text { NH American Indian and } \\
\text { Alaska Native }\end{array}$ & 0.2 & 0.0 & 0.5 & 3.7 & 0.8 \\
\hline NH Asian & 2.2 & 3.8 & 2.6 & 3.2 & 4.3 \\
\hline $\begin{array}{l}\text { NH Native Hawaiian and Other } \\
\text { Pacific Islander }\end{array}$ & 0.1 & 0.1 & 0.1 & 0.2 & 0.0 \\
\hline NH some other race & 0.1 & 0.2 & 0.1 & 0.1 & 0.2 \\
\hline $\mathrm{NH}$ two or more races & 1.7 & 3.4 & 1.8 & 1.6 & 2.4 \\
\hline \multicolumn{6}{|l|}{$\begin{array}{l}\text { Coalition-Committee } \\
\text { characteristics }\end{array}$} \\
\hline Coalition-committee size (n) & 18 & 15 & 12 & 11 & 13 \\
\hline $\begin{array}{c}\text { Bachelor's degree and above } \\
(\%)\end{array}$ & 50.0 & 50.0 & 18.0 & 27.0 & 11.0 \\
\hline Female $(\%)$ & 84.0 & 78.0 & 96.0 & 88.0 & 89.0 \\
\hline Target age & $0-18$ y & $0-18 \mathrm{y}$ & $0-8 \mathrm{y}$ & $0-18$ y & $0-5 y$ \\
\hline Coalition Focus Area(s) ${ }^{1}$ & $\begin{array}{l}\text { Policy, practice, } \\
\text { and environmental } \\
\text { change; Health } \\
\text { equity; WIC }{ }^{2} \\
\text { participation; } \\
\text { human-centered } \\
\text { messaging }\end{array}$ & $\begin{array}{l}\text { Increase utilization } \\
\text { of community } \\
\text { resources among } \\
\text { underserved } \\
\text { populations; } \\
\text { increasing youth } \\
\text { physical activity; } \\
\text { mental health }\end{array}$ & $\begin{array}{c}\text { Advocacy, } \\
\text { communications, } \\
\text { evaluation of early } \\
\text { care programs }\end{array}$ & $\begin{array}{l}\text { Improve school } \\
\text { programs to } \\
\text { increase access to } \\
\text { healthy foods and } \\
\text { physical activity } \\
\text { opportunities; } \\
\text { mental health }\end{array}$ & $\begin{array}{l}\text { Improve health } \\
\text { status of children } \\
0-5 \text { by increasing } \\
\text { resource } \\
\text { coordination across } \\
\text { the community }\end{array}$ \\
\hline
\end{tabular}

${ }^{1}$ Focus areas were determined through group model building activities. The focus areas were used in multiple correspondence analysis as part of coalition-committee dissimilarity measures. ${ }^{2}$ Special Supplemental Nutrition Program for Women, Infants, and Children.

\subsection{Procedures}

Each coalition-committee was administered the Stakeholder-driven Community Diffusion Survey to measure changes in knowledge of and engagement with obesity prevention. This survey has demonstrated reliability [73]. We focused on the social networks and individual sector affiliation of each coalition-committee member identified at baseline as well as the broader intervention system. The surveys asked coalition-committee members to list up to 20 people they discussed childhood obesity prevention with in the last three months constituting their social networks [68,73]; they were also asked to identify their sector affiliation. Individuals who were nominated via the survey were referred to as "first-degree alters" in accordance with social network theory [74]. These nominated individuals also became survey respondents in typical snowball or chain sampling fashion. Sampling concluded after second-degree alters were identified. To facilitate first-degree alter recruitment, the survey asked respondents to provide information about alters' setting/sector, organization, and title. Sector categories were generated through thematic analysis of open-ended sector affiliation questions. This information was used by the research team to acquire alters' email addresses from publicly available sources such as organization websites and in some cases confirmed with existing contact information of community partners. The American Community Survey was used to generate descriptive statistics of community characteristics used in the multidimensional analysis. Coalition-committee size, issue focus, and meeting frequency was gathered from meeting notes with each coalition-committee. 
Tufts University Institutional Review Board reviewed and approved this study (ethical approval codes for each community: 1833041, 19707023, 1908010, 00000844, 000001041).

\subsection{Analytical Methods}

Cross-sectional, undirected, social network analyses related to patterns of density, centralization, and homophily (i.e., degree and nominal assortativity) were conducted using iGraph in R across 5 communities in the US. Each CCN was converted from a directed network to an undirected network by using the "as.undirected" function in iGraph to collapse mutual pairs and combine edge attributes. Network characteristics were compared within and between communities: (1) Demographic (e.g., race/ethnicity, education attainment, and gender) differences between coalition-committee plus first degree alters (gathered from responses to the survey) and their communities (within system) were compiled across each of the 5 communities to generate a plot using multidimensional scaling analysis to see which coalitions cluster based on how similar or dissimilar they are to their community; (2) Coalition-committee characteristics (e.g., size, issue focus, meeting frequency) were compiled for each coalition-committee and compared across communities using multiple correspondence analysis to determine how similar or dissimilar each coalition-committee is to their community. Both the multidimensional analysis and the multiple correspondence analysis were conducted using R. Multiple correspondence analysis requires packages FactoMineR and Factoextra.

\subsubsection{Network Measures}

Network density, degree centralization, and assortativtity were calculated for each CCN. Network density is calculated by taking the total number of ties present in the network and dividing this number the number of possible ties. This yields a value between 0 and 1 , with values closer to one indicating a more tightly knit network. Analyses of within group densities were conducted to investigate whether there were discernible differences in patterns of density of Network A (coalition-committee plus first-degree alter ties), B (coalition-committee ties only), and C (first-degree alter ties only). Density is dependent on network size, and as a result larger networks typically have lower levels of density than smaller networks. Thus, the relative patterns of density are compared across coalition-committees rather than within coalition-committees.

Degree centralization assigns a score based on the number of links held by each node. It is calculated by taking the sum of the difference between the maximum centrality score observed in a network and all other observed centrality values and then dividing this sum by the maximum centrality value possible for all networks. Scores yielded are between 0 and 1, with scores closer to 1 indicating greater degree centralization. A network with high degree centralization means that some individuals have many connections to other individuals and those other individuals have relatively few connections. Degree centrality is visualized in Figure 1, where each node size is scaled based on its degree centrality score. For example, as seen in community 1's CCN (panel (a), nodes are larger, more prominent when compared to other CCNs due to the network's higher degree centralization).

Assortativity, or the bias in favor of connections between network nodes with similar characteristics, was calculated for network degree and sector heterogeneity. Degree assortativity is the Pearson correlation coefficient of degree between pairs of linked nodes. Positive values of $r$ indicate a correlation between nodes of similar degree, while negative values indicate relationships between nodes of different degree. In general, $r$ lies between -1 and 1 , where $r=1$ is perfect assortative mixing patterns, and $r=-1$ is a network that is completely disassortative. Nominal assortativity is similar but was used to calculate assortativity based on individual sector affiliation. Nominal assortativity of $r=1$ is perfect association between individuals of similar sector, and $r=-1$ is perfect disassortativity between individuals based on their sector affiliation. Finally, a K-core analysis was run on Network A of each CCN at baseline. In this study, a K-core analyses reveals the cluster of the most connected individuals, with each cluster or core revealing individuals who 
are more highly connected than the previous core. This analysis aided in assessing which sectors were represented among the most highly connected individuals in each CCN.

Legend

Network B - Committee Member Ties

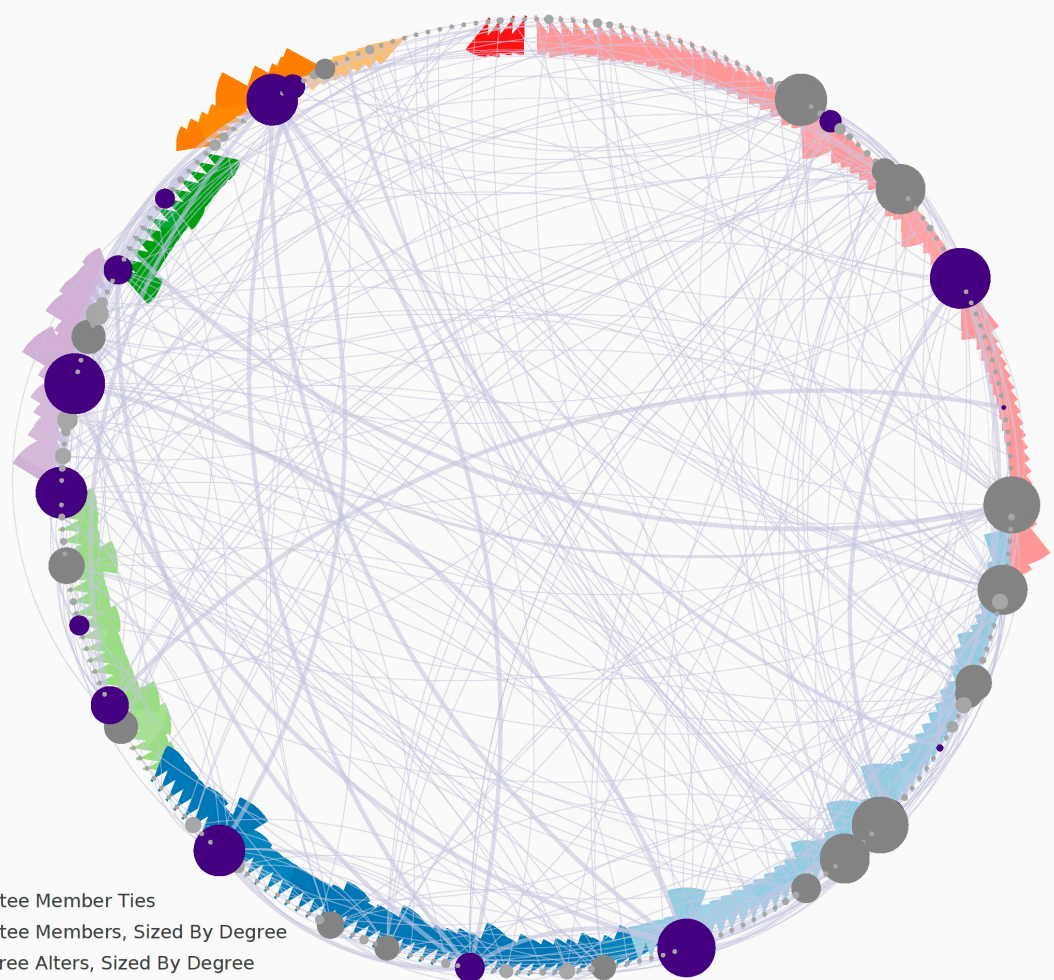

- Network C - 1st Degree Alters, Sized By Degree

Healthcare

- Early Education \& Schools

Local Government

- State Government

- Community-based Organization

- Parents \& Community Members

Private Sector

- Philanthropy

Academic Partner

(a)

Figure 1. Cont. 


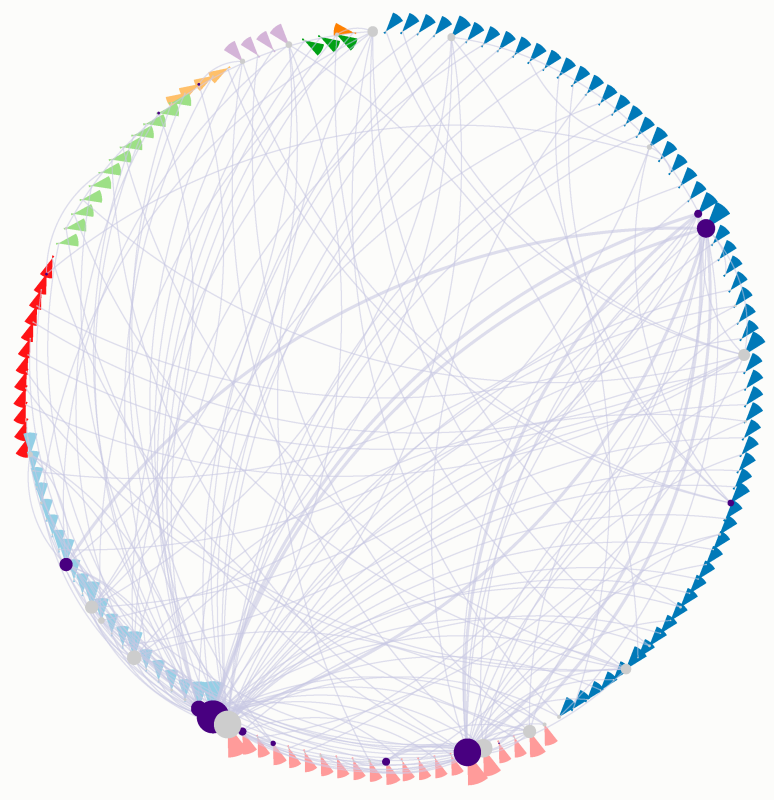

(b)

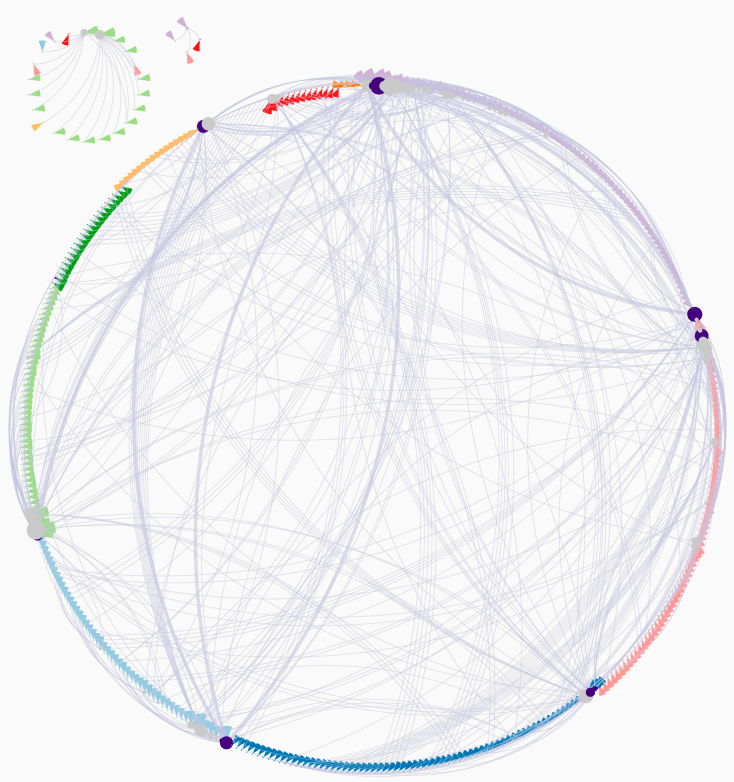

(d)

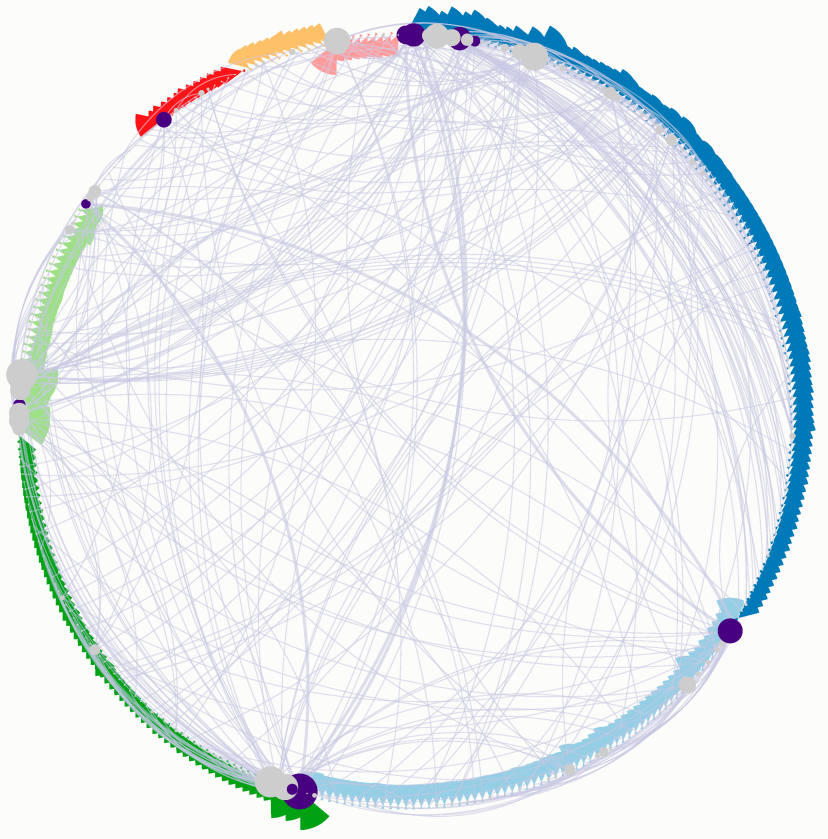

(c)

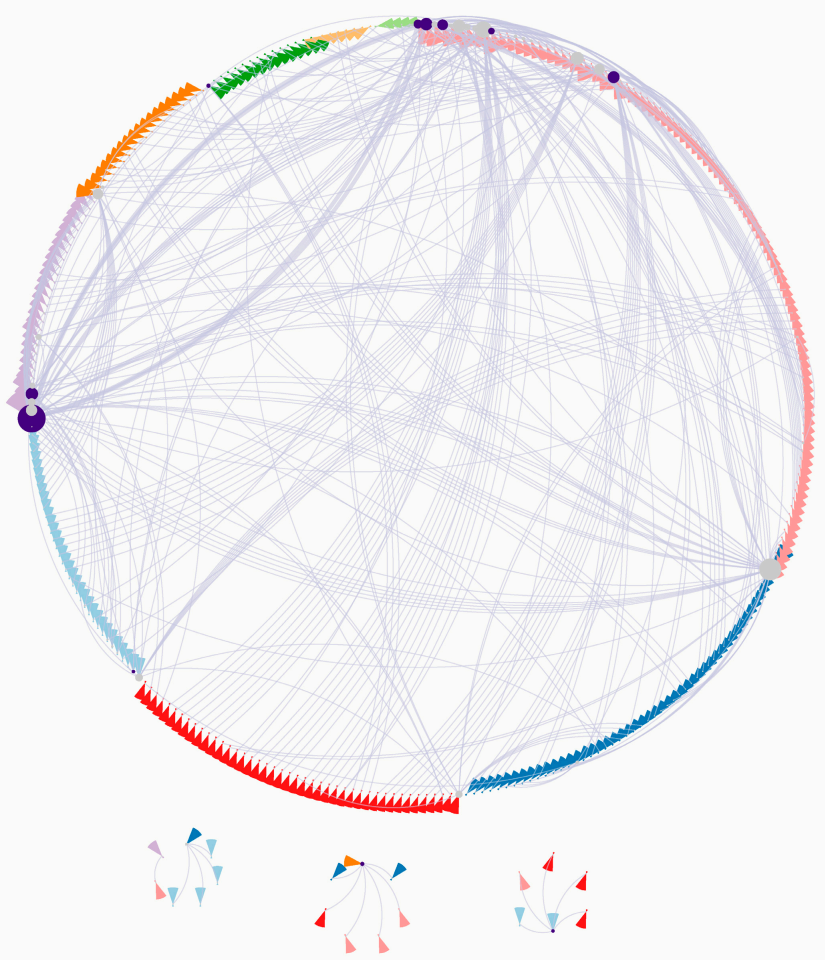

(e)

Figure 1. Baseline Structure and Characteristics of Communities 1-5. (a) Community 1, Network A; (b) Community 2, Network A; (c) Community 3, Network A; (d) Community 4, Network A; (e) Community 5, Network A. Panels a-e visualize overall coalition network (Network A) for each community included in the study. Nodes are sized by their level of degree (larger nodes have a higher degree), colored purple if the individual is on the coalition-committee (Network B), colored grey if first-degree alter (Network C), and grouped by sector affiliation. Each node has a "flag", a triangle attached to its side, colored to indicate sector (see panel (a) legend for sector color). Finally, thicker ties indicate connections between coalition-committee members only (Network B). 


\subsubsection{Multidimensional Scaling Analysis}

Multidimensional scaling analysis (MSA) is a data analysis process that groups data into data dimensions and measurements. Dimensions are categories used to classify data such as geography and time. In this case, the dimensions are the percent difference between the following CCN and community characteristics: race/ethnicity, education level, and gender. These characteristics were used to see which CCNs cluster based on how similar or dissimilar they are to their respective community. This clustering tells us whether there are similarities across coalitions that should be considered when designing coalition interventions. Reviewing clusters may help determine why two coalitions that have similar outcomes cluster together based on their community attribute distribution. The clustering may inform interventions that are underway, altering them to cluster among different individuals to achieve diffusion in a specific direction.

\subsubsection{Multiple Correspondence Analysis}

Multiple correspondence analysis (MCA) was used to compare each $\mathrm{CCN}$, to explore whether there were any similarities across each Network A based on coalition-committee characteristics. MCA uses nominal categorical data to detect underlying structures in a data set by representing the data in a low-dimensional space. In this correspondence analysis, the algorithm uses a CCN by variables matrix, where rows are the CCNs and columns are the categories of the variables. Associations between variables are uncovered by calculating the chi-square distance between different categorical variables and the CCNs. Associations and hierarchies between individuals (in this case CCNs) are uncovered by extending the multiple correspondence analysis to include hierarchical clustering outputs and again calculating the chi-square distance between different CCNs. Coalition-committee characteristics (e.g., CCN size, issue focus, and meeting frequency, each gathered from meeting notes) were compiled for each coalition-committee and compared across CCNs using MCA to determine how each CCN is similar or dissimilar. The following were the included coalition-committee characteristics: coalition-committee size (below 15 or 15 and above, to half the coalition-committees based on size); coalition-committee members' role within their organization (director, programmatic, or a mix); meeting frequency (monthly, biweekly, or weekly); and, finally, various coalition focus areas such as health equity, cross-sector collaboration, community mobilization, and food security.

\section{Analysis and Results}

Survey recruitment ranged from 195 (community 5) to 405 (community 4). Table 2 reports the results of each network measure. Figure 1 visualizes each network based on these measures.

\subsection{Social Network Analysis}

\subsubsection{Density}

Comparing across CCNs, overall network density (Network A) is similar for communities A, C, and E (0.012) with communities B and D being roughly half the others' density (0.006). Comparing Network A to Network B, Network B is denser (communities $B, C$, and E). Network $C$ is consistently less dense compared to Network B and $\mathrm{A}$; baseline connections between first-degree alters alone are less frequent than baseline connections between coalition-committee members (Network B) or baseline connections between coalition-committee members and first-degree alters (Network A). Comparing within each coalition, Network B is denser than either Network A or C. 
Table 2. Summary of baseline network results.

\begin{tabular}{|c|c|c|c|c|c|c|}
\hline & $\begin{array}{l}\text { Network } \\
\text { Measure }\end{array}$ & $\begin{array}{l}\text { Community } 1 \\
\qquad(\mathrm{n}=343)^{1}\end{array}$ & $\begin{array}{l}\text { Community } 2 \\
\qquad(n=236)\end{array}$ & $\begin{array}{l}\text { Community } 3 \\
\quad(n=311)\end{array}$ & $\begin{array}{l}\text { Community } 4 \\
\qquad(\mathrm{n}=405)\end{array}$ & $\begin{array}{c}\text { Community } 5 \\
(n=195)\end{array}$ \\
\hline \multirow{4}{*}{$\begin{array}{c}\text { Network A: } \\
\text { Coalition- } \\
\text { committee + first } \\
\text { degree alters }\end{array}$} & Density & 0.012 & 0.006 & 0.006 & 0.012 & 0.012 \\
\hline & $\begin{array}{c}\text { Degree } \\
\text { Centralization }\end{array}$ & 0.081 & 0.083 & 0.007 & 0.055 & 0.096 \\
\hline & $\begin{array}{c}\text { Degree } \\
\text { Assortativity }\end{array}$ & -0.37 & -0.51 & -0.40 & -0.41 & -0.52 \\
\hline & $\begin{array}{c}\text { Nominal (Sector) } \\
\text { Assortativity }\end{array}$ & 0.16 & -0.05 & -0.15 & 0.28 & -0.12 \\
\hline \multirow{4}{*}{$\begin{array}{l}\text { Network B: } \\
\text { Coalition- } \\
\text { committee } \\
\text { only }\end{array}$} & Density & 0.088 & 0.024 & 0.077 & 0.054 & 0.013 \\
\hline & $\begin{array}{c}\text { Degree } \\
\text { Centralization }\end{array}$ & 0.301 & 0.123 & 0.141 & 0.145 & 0.071 \\
\hline & $\begin{array}{c}\text { Degree } \\
\text { Assortativity }\end{array}$ & -0.23 & -0.67 & -0.04 & -0.50 & -0.09 \\
\hline & $\begin{array}{c}\text { Nominal (Sector) } \\
\text { Assortativity }\end{array}$ & -0.10 & -0.28 & -0.02 & -0.06 & -1 \\
\hline \multirow{4}{*}{$\begin{array}{l}\text { Network C: First } \\
\text { degree alters only }\end{array}$} & Density & 0.004 & 0.005 & 0.020 & 0.005 & 0.007 \\
\hline & $\begin{array}{c}\text { Degree } \\
\text { Centralization }\end{array}$ & 0.062 & 0.118 & 0.027 & 0.046 & 0.097 \\
\hline & $\begin{array}{c}\text { Degree } \\
\text { Assortativity }\end{array}$ & -0.49 & -0.51 & -0.46 & -0.54 & -0.60 \\
\hline & $\begin{array}{c}\text { Nominal (Sector) } \\
\text { Assortativity }\end{array}$ & -0.02 & -0.19 & -0.10 & -0.12 & -0.10 \\
\hline
\end{tabular}

${ }^{1} n$ is the total unique vertices in each overall network (coalition-committee + first degree alters) at baseline.

\subsubsection{Degree Centralization}

Comparing across CCNs, community 3 has a lower degree centralization for Network A. For Network B, community 1 has approximately three times greater degree centralization than other coalition-committees. Conversely, community 5 has approximately three times fewer degree centralization than three other coalition-committees. For Network C, community 2's first-degree alters had fewer connections than other coalition-committees while community 5 has greater connections among their first-degree alters only. Comparing within CCNs, the general trend is higher degree centralization for the committee-only network (Network B) and lower degree centralization for first-degree alters (Network C). One exception is in community 5's CCN which has greater degree centralization among its first-degree alters as well as the overall CCN (Network A); coalition-committee members tend to have more connections to their first-degree alters than to other coalition-committee members at the beginning of the SDCD informed intervention; and first-degree alters tend to have more connections to other named first-degree alters.

\subsubsection{Homophily}

Comparing across CCNs on degree assortativity, the general trend for each network is negative, meaning individuals are generally connected to others of different degree (i.e., others who are connected to a different number of individuals). This trend is less so for communities 3 and 5's coalition-committee-only network (Network B), where we see lower degree assortativity when compared to other CCNs. When comparing within $\mathrm{CCNs}$, the same trend appears; the $\mathrm{CCN}$ for communities 3 and 5 are comparatively more disassortative. Comparing across CCNs on nominal (sector) assortativity (visualized in Figure 1 as node flag colors), communities 1 and 3 CCNs (Network A) show a correlation between nodes of different sector affiliation. This trend does not hold true for Networks $B$ and $C$.

\subsubsection{K-Core}

Community 4 had five cores; communities 1, 2, and 3 had four cores; and community 5 had three. For community 1's highest core, the early childhood and education sector was represented the most $(30.7 \%)$ and the community-based organization sector and the academic sector were both represented the second most (23\%). For community 2 's 
highest core, healthcare was a majority of sector representation (50\%) and community-based organizations came in as the second most prevalent sector (33\%). For community 3 's highest core, the early education and academic sectors made up a majority of sector representation (each 27\%). Community 4's highest core showed that academic partners made up most of the sector representation (48\%) with healthcare making up $23 \%$. Finally, community 5 's highest core was 50\% academic partner sector and 25\% community-based organization.

\subsection{Multidimensional Scaling Analysis}

The MSA (illustrated in Figure 2) revealed one plausible cluster between communities 3,4 , and 5. That is, this cluster contains CCNs that are similar in their coalition-committee and community race/ethnicity, education level, and gender differences. The other two coalitions do not cluster with one another; based on the included CCN and community characteristics, they do not have comparable dissimilarities.

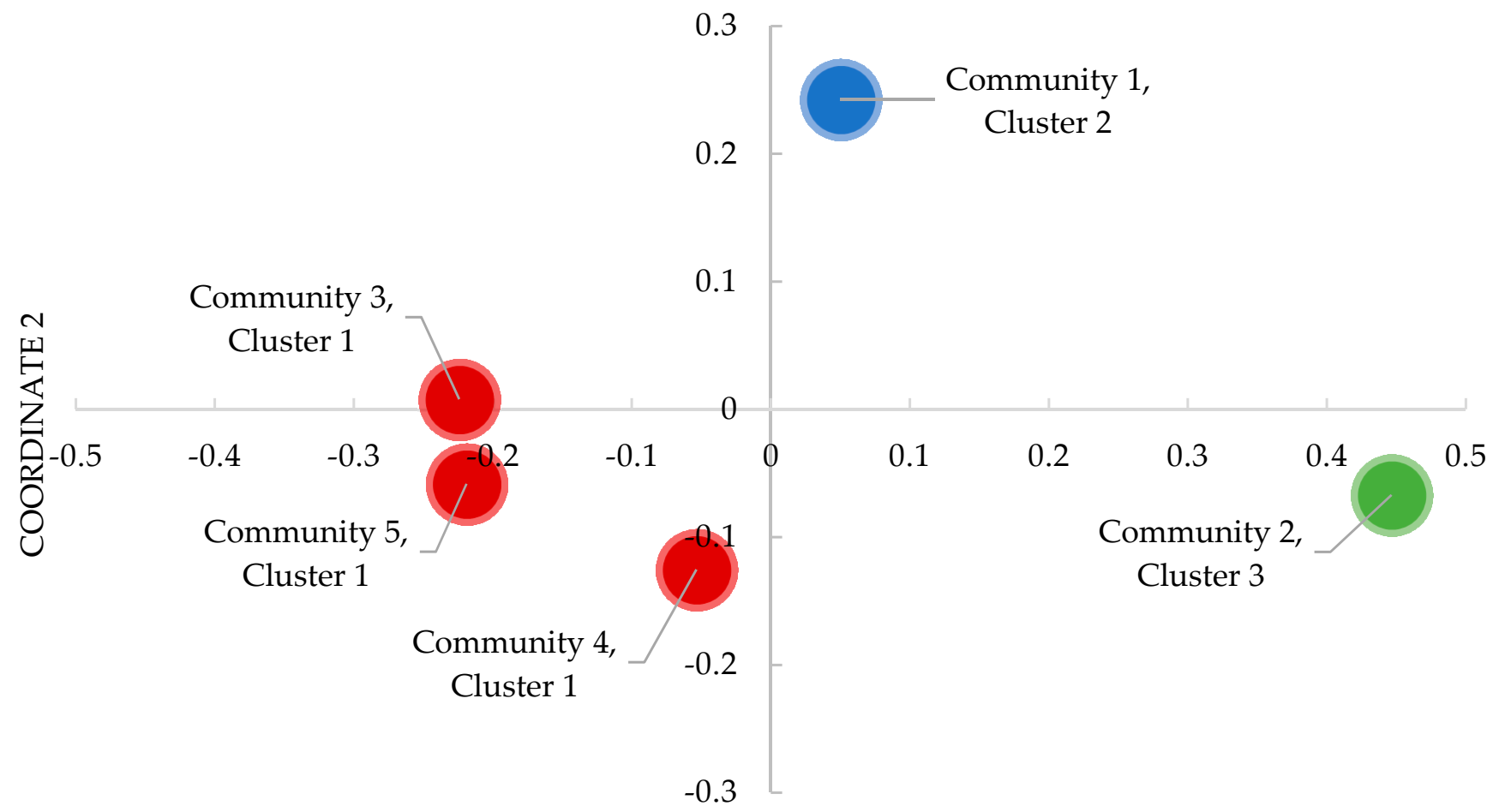

\section{COORDINATE 1}

Figure 2. Multidimensional Scaling Analysis of Cross-Community Coalition Network Dissimilarity. Clusters represent Euclidean distances between CCNs that have similar dissimilarities.

\subsection{Multiple Correspondence Analysis}

Based on the multiple correspondence analysis scree plot of explained variance, $65 \%$ variance is explained by the first two dimensions, the first dimension being the most important, explaining the most variance, and the second dimension being the second most important, accounting for the second most variance. As seen in Table 3, the biplot of CCNs and representative categorical variables indicates clustering for communities 4 and 5 CCNs based on meeting frequency (i.e., biweekly), whether their coalition-committee was newly formed (i.e., both are newly formed), and the level of coalition-committee membership (i.e., programmatic and director). It also indicates clustering for communities 2 and 3 based on meeting frequency and a focus on health equity and cross-sector collaboration. The hierarchical clustering map indicates a similar trend, where there are three optimal coalitioncommittee clusters: (1) communities 4 and 5; (2) communities 2 and 3; and (3) community 1. Community 1's CCN does not cluster with another CCN based on their areas of focus 
as well as their coalition-committee size (above 15) and coalition-committee membership (director level). These results indicate that there are similarities across coalition-committees and their networks. These similarities may need to be taken in account when analyzing coalition-committee network changes over time behavior [37]. Explaining variations in coalition-committee characteristics over time may help explain variation in intervention effects on individual and group behavior.

Table 3. Summary of multiple correspondence analysis cluster results.

\begin{tabular}{|c|c|c|}
\hline Community & Cluster & Variables Informing Each Cluster \\
\hline Community 1 & Cluster 1 & $\begin{array}{l}\text { Coalition-committee focus on WIC (Special Supplemental } \\
\text { Nutrition Program for Women, Infants, and Children) }\end{array}$ \\
\hline $\begin{array}{l}\text { Community } 2 \\
\text { Community } 3\end{array}$ & Cluster 2 & $\begin{array}{c}\text { Meeting frequency; coalition-committee focus } \\
\text { (cross-sector collaboration) }\end{array}$ \\
\hline $\begin{array}{l}\text { Community } 4 \\
\text { Community } 5\end{array}$ & Cluster 3 & $\begin{array}{l}\text { Meeting frequency; newly formed coalition-committee; level of } \\
\text { coalition-committee membership }\end{array}$ \\
\hline
\end{tabular}

\section{Discussion}

Using social network analysis, multidimensional scaling analysis, and multiple correspondence analysis in this study begins to demonstrate that baseline CCN structure and characteristics can differ. Further research examining the implications of these differences on coalition-committee function and interventions involving coalitions is warranted. The findings in this study illustrate that coalition-committee members and their first-degree alters, which includes members of larger coalition in four out of five communities, have substantial heterogeneity and have underlying or "hidden" features ([75]; Table 4). The baseline structure and characteristics of CCNs was hypothesized to vary based on their composition, and when compared to other CCNs in our sample working in childhood obesity prevention, in several ways.

First, it was expected that CCNs that were drawn from existing coalitions would demonstrate higher baseline levels of density, degree centralization, and degree assortativity (H1). Second, sector affiliation was expected to be heterogeneous across coalitioncommittees and their first degree alters (H2). Third, coalition-committees were hypothesized to cluster with each other based on a) their within-coalition-committee characteristics and b) their coalition-committee-community dissimilarity ( $\mathrm{H} 3$ and $\mathrm{H} 4$, respectively). Overall, these hypotheses were supported.

Building on these findings, the remainder of the discussion (1) explores the meaning of baseline CCN structure when conceptualizing coalition-committees as network interventions in the context of their broader coalitions and communities; (2) explores the utility of these analyses and results for informing both network interventions and the feasibility of PPE strategy implementation; (3) examines the utility of these analyses for use in iterative coalition-committee feedback and development. 
Table 4. Summary of outcomes by hypothesis.

\section{Hypothesis \\ H1: CCNs within each of the five communities will demonstrate similar levels of density, degree centralization, and degree assortativity.}

Social network analysis: density, degree centralization, degree assortativity.

Social network analysis and $\mathrm{K}$-core analysis.

display sector heterogeneity and nominal (sector) assortativity.

H3: Obesity prevention coalition-committees across participating communities will be similar based on a set of CCN characteristics including coalition-committee size, frequency in meeting, and focus.

H4A: When compared to the communities in which they are embedded,

coalition-committees will

cluster based on their

coalition-committee-

community dissimilarity,

which includes variables on race/ethnicity, educational

level, and gender.

H4B: CCNs will cluster based on their

within-coalition-committee similarity.
Multidimensional scaling analysis.

Multidimensional scaling analysis.
Multiple correspondence analysis

Potential Network

Intervention [76]
This hypothesis was supported. CCN density, degree centralization, and degree assortativity were similar across communities. However, these network measures varied when compared within each $\mathrm{CCN}$ (Network B to Network C). This hypothesis was partially supported. Network A across CCNs displayed sector heterogeneity. Two CCNs had early education and schools and healthcare sector majority, three did not. The academic and community-based organization sectors both had notable representation.

This hypothesis was not supported. CCNs tended to cluster with other $\mathrm{CCNs}$ based on these characteristics, but in no particular pattern.

This hypothesis was supported. Three CCNs clustered on their coalitioncommittee-community dissimilarity based on race/ethnicity, education level, and gender.

This hypothesis was supported. Three clusters emerged: (1) communities 4 and 5; (2) communities 2 and

3 ; (3) and community 1.
Segmentation *, or an approach that identifies groups of people that can be recruited to change network properties, can be used to bolster existing density levels, or expand density levels to other groups.

Depending on the level of sector heterogeneity, Induction, or interventions that facilitate peer-to-peer interaction, can

be used to introduce and connect individuals from different sectors.

Depending on the goal of the intervention,

coalition-committee size, meeting frequency, and focus can be shaped or altered using baseline network data in what is known as Individuals network intervention.

Alteration, or deliberately altering the network to improve desired network composition, may be used here to decrease coalitioncommittee-community dissimilarity. Alteration, or deliberately
altering the network to
improve desired network
composition, may be used
here to shift
coalition-committee similarity.

* Note. More information on network intervention typology referred to in this table can be found in Valente and colleagues' paper on network interventions [77].

While conceptualizing community coalitions as an intervention that is theorized to have cascading effects on the broader intervention system has been previously explored [41,78], examining baseline structure across several CCNs more closely to bolster that conceptualization has not. Indeed, an emerging consensus of community coalition structure and mobilization explores coalitions as intentional, bounded networks within complex intervention systems. Research in this form generally explores coalitions as inter-organizational networks $[77,79]$; individuals embedded in a broader system of organizations to intervene on a targeted issue [4]; as well as more structured, goal-directed networks. Conceptually, this paper combines aspects of each approach to community coalition structure and mobilization and adds cross-sectional dimension by exploring baseline 
$\mathrm{CCN}$ characteristics, especially within a centralized core or a coalition-committee within the coalition. For example, our K-core analysis (H2) indicates that the most connected individuals display greater sector heterogeneity, providing increased cross-sector collaboration. In another example, individuals in communities 1 and $3 \mathrm{CCNs}^{\prime}$ are relating to others outside of their respective sector. Baseline $\mathrm{CCN}$ characteristics play a role in this conceptualization as well. From our multidimensional scaling and multiple correspondence analyses, CCNs are diverse but patterned. Conceptualizing coalition-committees as network interventions for childhood obesity prevention should account for both differences between coalitioncommittee and community demographics as well as similarities in coalition-committee characteristics (e.g., size, focus) across discrete geographies.

Network interventions have received increased attention in the last decade $[75,80,81]$. For example, Valente and colleagues [76] describes four intervention types where network data is used to identify individuals to act as champions (individual); direct the intervention toward specific groups of people (segmentation); create intentional and novel peer interactions (induction); and alter the network in some way (alteration). As applied in Table 4, baseline $\mathrm{CCN}$ structure and characteristics reported here would theoretically, directly influence the design of network interventions of any of these types in several ways. First, initial assessments of CCNs may change the type of network intervention amenable for a specific context and among a specific coalition population. For example, our results indicate that baseline levels of density are higher within coalition-committees rather than across the CCN itself; network interventions focused on creating peer interactions, or segmentation, would need to select specific peers outside of the coalition-committee for coalition-committee members to interact with to increase density. In another example, our results indicate that coalition-committee members may differ from the broader community in which their coalitions are embedded in terms of demographic characteristics such as race/ethnicity, education level, and gender. These differences can hinder implementation of interventions, particularly health equity-oriented interventions where the populations that experience health disparities (often Black, Indigenous, and People of Color and low income) differ from those typically in community coalitions (often white and college educated).

Our analyses indicate that more research is needed to understand how baseline CCN structure and characteristics influence the feasibility of PPE strategy implementation. In a review by Korn and colleagues [30], researchers found that childhood obesity prevention interventions that involved coalitions tended to engage community members in a greater number of research phases and perceived coalition pacts included community capacity building and intervention sustainability. Given the increase in childhood obesity prevention interventions engaging community coalitions in problem identification, design and planning, implementation, evaluation, dissemination, and sustainability, baseline coalitioncoalition-committee structure and characteristics need to be considered to provide initial estimates of intervention feasibility at each phase. Though the interventions included in the review are not network interventions, network composition and characteristics may have influenced the results reported in each study. For example, one study, Romp and Chomp [82], created a capacity building and environmental change intervention to promote healthy eating and active play in early education and care settings backed by a multi-sector management coalition-committee representing academia, healthcare, local government, early education, recreation, local health departments, and oral health. A decrease in BMI z-scores among 3-4-year-old children was seen, but how community coalition structure and characteristics may have influenced that decrease is unknown. Results from our study on sector heterogeneity suggests that researchers need to test whether implementation of PPE change interventions should consider the baseline nature of CCNs, to account for confounding or moderating effects on the achievement of positive childhood health outcomes.

Finally, results from this study may have important implications for providing iterative feedback to community partners during childhood obesity prevention interventions. Researchers engage coalitions and/or committees in community-based childhood obesity 
prevention interventions in many aspects of the research process. During this engagement, community-based researchers often provide iterative feedback to community partners in the form of preliminary research findings or other informal reports [4]. Our results indicate that the assessment of baseline $\mathrm{CCN}$ structure and characteristics may be important information for community partners, and researchers, to use in (a) curtailing or expanding coalition activities or PPE strategies; and/or (b) rethinking their approach to cross-sector collaboration. While knowing whether a coalition has a sparse network (or low density) may not help stakeholders with targeting their PPE strategies, being able to identify pockets of greater density in the coalition than others in a sparse network may guide stakeholders on whom to engage more intentionally. In a similar manner, information on baseline sector representation (H2) may help community partners make decisions on which sector needs to be represented in a strategic meeting. Future research in this area should examine how the use of baseline $\mathrm{CCN}$ structure and characteristics can be used to bolster coalition PPE efforts. In addition, because purposeful network alterations can be resource intense, future research should focus on developing tools for rapid baseline analysis and result dissemination to community partners.

\section{Study Limitations}

First, the findings in this study may not be generalizable beyond coalition-committees and coalitions similar to those who participated. Our use of data from five communities is however a strength compared to a single case study. Findings can inform theory related to community coalitions' contributions to intervention systems and research on community coalitions as networks. Second, given the nature of complex systems, there are surely other structures and characteristics important to the examination of baseline $\mathrm{CCN}$ composition that we did not include in this study. Third, the number of recruited participants was smaller than the intended baseline sample. Thus, Network A, which consists of coalition-committee members and their first-degree alters, is not representative of the entire coalitions or professional network working on childhood obesity prevention in a community. Finally, the coalition-committees convened for our intervention may not represent coalition-committees that are formed under different circumstances.

\section{Conclusions}

The examination of baseline CCNs is an important step in determine the potential role network structure plays in childhood obesity prevention interventions. Our results indicate that implementation may need to consider the heterogeneity of CCN structure and characteristics. This may be especially true when designing and implementing a network intervention that aims to influence CCN structure and characteristics. Though there were similarities across included CCNs in this study, investigators could use baseline $\mathrm{CCN}$ structure and characteristics as data to tailor their interventions to local contexts. For example, leaders and other highly influential individuals identified at baseline could be subsequently and purposefully introduced to the network to create more meaningful changes to network hierarchy. These changes may help community coalitions address local issues by leveraging the social context to enhance existing and form new partnerships. Future work in this area should consider $\mathrm{CCN}$ structure and characteristics longitudinally.

Author Contributions: Conceptualization, T.R.M. and M.C.P.; methodology, T.R.M. and M.C.P.; investigation, L.C. and C.D.E.; data curation, T.R.M.; formal analysis, T.R.M.; visualization, T.R.M.; writing-original draft preparation, T.R.M.; writing—review and editing, T.R.M., M.C.P., L.C., A.R.K., E.H. and C.D.E.; supervision, C.D.E.; funding acquisition, C.D.E. and E.H. All authors have read and agreed to the published version of the manuscript.

Funding: This research was funded by The JPB Foundation, grant number PRO626.

Institutional Review Board Statement: The study was conducted according to the guidelines of the Declaration of Helsinki, and approved by the Institutional Review Board of Tufts University (protocol code 00000844; approved 11 August 2020). 
Informed Consent Statement: Informed consent was obtained from all subjects involved in the study.

Data Availability Statement: The data and code presented in this study are available on request from the first author with appropriate inter-institutional agreement. The data are not publicly available due to privacy restrictions.

Conflicts of Interest: The authors declare no conflict of interest. The funders had no role in the design of the study; in the collection, analyses, or interpretation of data; in the writing of the manuscript, or in the decision to publish the results. Any opinions, findings, conclusions, or recommendations expressed in this publication are those of the authors and do not necessarily reflect the view of the U.S. Department of Health and Human Services, the National Institutes of Health, or the National Cancer Institute.

\section{References}

1. Bell, A.C.; Simmons, A.; Sanigorski, A.M.; Kremer, P.J.; Swinburn, B.A. Preventing Childhood Obesity: The Sentinel Site for Obesity Prevention in Victoria, Australia. Health Promot. Int. 2008, 23, 328-336. [CrossRef]

2. Economos, C.D.; Hyatt, R.R.; Must, A.; Goldberg, J.P.; Kuder, J.; Naumova, E.N.; Collins, J.J.; Nelson, M.E. Shape Up Somerville Two-Year Results: A Community-Based Environmental Change Intervention Sustains Weight Reduction in Children. Prev. Med. 2013, 57, 322-327. [CrossRef]

3. Kegler, M.C.; Rigler, J.; Honeycutt, S. How Does Community Context Influence Coalitions in the Formation Stage? A Multiple Case Study Based on the Community Coalition Action Theory. BMC Public Health 2010, 10, 90. [CrossRef]

4. Butterfoss, F.D.; Kegler, M.C. A Coalition Model for Community Action. In Community Organizing and Community Building for Health and Welfare; Minkler, M., Ed.; Rutgers University Press: New Brunswick, NJ, USA, 2012; p. 21.

5. Rutter, H.; Savona, N.; Glonti, K.; Bibby, J.; Cummins, S.; Finegood, D.T.; Greaves, F.; Harper, L.; Hawe, P.; Moore, L.; et al. The Need for a Complex Systems Model of Evidence for Public Health. Lancet 2017, 390, 2602-2604. [CrossRef]

6. Williams, K.J.; Gail Bray, P.; Shapiro-Mendoza, C.K.; Reisz, I.; Peranteau, J. Modeling the Principles of Community-Based Participatory Research in a Community Health Assessment Conducted by a Health Foundation. Health Promot. Pract. 2009, 10, 67-75. [CrossRef]

7. Hales, C.M. Prevalence of Obesity Among Adults and Youth: United States, 2015-2016; National Center for Health Statistics: Hyattsville, MD, USA, 2017; p. 8.

8. Weihrauch-Blüher, S.; Wiegand, S. Risk Factors and Implications of Childhood Obesity. Curr. Obes. Rep. 2018, 7, 254-259. [CrossRef]

9. Appel, J.M.; Fullerton, K.; Hennessy, E.; Korn, A.R.; Tovar, A.; Allender, S.; Hovmand, P.S.; Kasman, M.; Swinburn, B.A.; Hammond, R.A.; et al. Design and Methods of Shape Up Under 5: Integration of Systems Science and Community-Engaged Research to Prevent Early Childhood Obesity. PLoS ONE 2019, 14, e0220169. [CrossRef]

10. Watson-Thompson, J.; May, M.J.; Jefferson, J.; Young, Y.; Young, A.; Schultz, J. Examining the Contributions of a Community Coalition in Addressing Urban Health Determinants. J. Prev. Interv. Community 2018, 46, 7-27. [CrossRef]

11. Vlahov, D.; Freudenberg, N.; Proietti, F.; Ompad, D.; Quinn, A.; Nandi, V.; Galea, S. Urban as a Determinant of Health. J. Urban Health 2007, 84, 16-26. [CrossRef]

12. WHO. Our Cities, Our Health, Our Future: Acting on Social Determinants for Health Equity in Urban Settings. Report to the WHO Commission on Social Determinants of Health from the Knowledge Network on Urban Settings; WHO: Geneva, Switzerland, 2008.

13. Kegler, M.C.; Norton, B.L.; Aronson, R. Achieving Organizational Change: Findings from Case Studies of 20 California Healthy Cities and Communities Coalitions. Health Promot. Int. 2008, 23, 109-118. [CrossRef]

14. Brownson, R.C.; Haire-Joshu, D.; Luke, D.A. Shaping the Context of Health: A Review of Environmental and Policy Approaches in the Prevention of Chronic Diseases. Annu. Rev. Public Health 2006, 27, 341-370. [CrossRef]

15. Desjardins, E.; Schwartz, A.L. Collaborating To Combat Childhood Obesity. Health Aff. 2007, 26, 567-571. [CrossRef]

16. Stirling, A.; Lobstein, T.; Millstone, E. Methodology for Obtaining Stakeholder Assessments of Obesity Policy Options in the PorGrow Project. Obes. Rev. 2007, 8, 17-27. [CrossRef] [PubMed]

17. Summerbell, C.D.; Waters, E.; Edmunds, L.; Kelly, S.A.; Brown, T.; Campbell, K.J. Interventions for Preventing Obesity in Children. Cochrane Database Syst. Rev. 2005, 3. [CrossRef]

18. Hill, J.O.; Peters, J.C.; Wyatt, H.R. The Role of Public Policy in Treating the Epidemic of Global Obesity. Clin. Pharmacol. Ther. 2007, 81, 772-775. [CrossRef] [PubMed]

19. Popkin, B.M.; Duffey, K.; Gordon-Larsen, P. Environmental Influences on Food Choice, Physical Activity and Energy Balance. Physiol. Behav. 2005, 86, 603-613. [CrossRef]

20. Lee, V.; Mikkelsen, L.; Srikantharajah, J.; Cohen, L. Promising Strategies for Creating Healthy Eating and Active Living Environments. 2008. Available online: https://www.preventioninstitute.org/sites/default/files/publications/promisingstrategies.pdf (accessed on 21 June 2021).

21. Communities Putting Prevention to Work Program Group; Bunnell, R.; O’Neil, D.; Soler, R.; Payne, R.; Giles, W.H.; Collins, J.; Bauer, U. Fifty Communities Putting Prevention to Work: Accelerating Chronic Disease Prevention Through Policy, Systems and Environmental Change. J. Community Health 2012, 37, 1081-1090. [CrossRef] 
22. Mansergh, G.; Rohrbach, L.A.; Montgomery, S.B.; Pentz, M.A.; Johnson, C.A. Process Evaluation of Community Coalitions for Alcohol and Other Drug Abuse Prevention: A Case Study Comparison of Researcher- and Community-Initiated Models. J. Community Psychol. 1996, 24, 118-135. [CrossRef]

23. Lee, P.R.; Fuccillo, R.; Wolff, T.J. Key Components of a Statewide Healthy Communities Effort. Public Health Rep. 2000, 115, 134-138. [CrossRef]

24. Christens, B.D.; Inzeo, P.T.; Meinen, A.; Hilgendorf, A.E.; Berns, R.; Korth, A.; Pollard, E.; McCall, A.; Adams, A.; Stedman, J. Community-Led Collaborative Action to Prevent Obesity. WMJ 2016, 115, 6.

25. Meinen, A.; Hilgendorf, A.; Korth, A.L.; Christens, B.D.; Breuer, C.; Joyner, H.; Polzin, M.; Adams, A.; Wolfe, D.; Braun, A.; et al. The Wisconsin Early Childhood Obesity Prevention Initiative: An Example of Statewide Collective Impact. WMJ 2016, 115, 7.

26. Frerichs, L.M.; Araz, O.M.; Huang, T.T.-K. Modeling Social Transmission Dynamics of Unhealthy Behaviors for Evaluating Prevention and Treatment Interventions on Childhood Obesity. PLoS ONE 2013, 8, e82887. [CrossRef]

27. Benton, J.S.; Anderson, J.; Hunter, R.F.; French, D.P. The Effect of Changing the Built Environment on Physical Activity: A Quantitative Review of the Risk of Bias in Natural Experiments. Int. J. Behav. Nutr. Phys. Act. 2016, 13, 107. [CrossRef] [PubMed]

28. Luke, D.A.; Hammond, R.A.; Combs, T.; Sorg, A.; Kasman, M.; Mack-Crane, A.; Ribisl, K.M.; Henriksen, L. Tobacco Town: Computational Modeling of Policy Options to Reduce Tobacco Retailer Density. Am. J. Public Health 2017, 107, 740-746. [CrossRef]

29. Prüss-Üstün, A.; Wolf, J.; Corvalán, C.; World Health Organization; Bos, R.; Neira, D.M. Preventing Disease through Healthy Environments: A Global Assessment of the Burden of Disease from Environmental Risks; World Health Organization: Geneva, Switzerland, 2016; ISBN 978-92-4-156519-6.

30. Korn, A.R.; Hennessy, E.; Tovar, A.; Finn, C.; Hammond, R.A.; Economos, C.D. Engaging Coalitions in Community-Based Childhood Obesity Prevention Interventions: A Mixed Methods Assessment. Child. Obes. 2018, 14, 537-552. [CrossRef] [PubMed]

31. Benjamin Neelon, S.E.; Namenek Brouwer, R.J.; Østbye, T.; Evenson, K.R.; Neelon, B.; Martinie, A.; Bennett, G. A CommunityBased Intervention Increases Physical Activity and Reduces Obesity in School-Age Children in North Carolina. Child. Obes. 2015, 11, 297-303. [CrossRef]

32. Pettman, T.L.; Armstrong, R.; Allender, S.; Love, P.; Gill, T.; Coveney, J.; Boylan, S.; Booth, S.; Bolton, K.; Swinburn, B. Evaluation of a Knowledge Translation and Exchange Platform to Advance Non-Communicable Disease Prevention. Evid. Policy 2016, 12, 109-126. [CrossRef]

33. Olson, C.M.; Baker, I.R.; Demment, M.M.; Graham, M.L.; May, J.J.; Strawderman, M.S.; Wells, N.M. The Healthy Start Partnership: An Approach to Obesity Prevention in Young Families. Fam. Community Health 2014, 37, 74-85. [CrossRef] [PubMed]

34. Economos, C.D.; Curtatone, J.A. Shaping up Somerville: A Community Initiative in Massachusetts. Prev. Med. 2010, 50, S97-S98. [CrossRef] [PubMed]

35. Blanchet, K.; Palmer, J.; Palanchowke, R.; Boggs, D.; Jama, A.; Girois, S. Advancing the Application of Systems Thinking in Health: Analysing the Contextual and Social Network Factors Influencing the Use of Sustainability Indicators in a Health System-A Comparative Study in Nepal and Somaliland. Health Res. Policy Syst. 2014, 12, 46. [CrossRef] [PubMed]

36. Palinkas, L.A.; Holloway, I.W.; Rice, E.; Fuentes, D.; Wu, Q.; Chamberlain, P. Social Networks and Implementation of EvidenceBased Practices in Public Youth-Serving Systems: A Mixed-Methods Study. Implement. Sci. 2011, 6, 113. [CrossRef]

37. Valente, T.W.; Palinkas, L.A.; Czaja, S.; Chu, K.-H.; Brown, C.H. Social Network Analysis for Program Implementation. PLoS ONE 2015, 10, e0131712. [CrossRef]

38. Palinkas, L.A.; Fuentes, D.; Finno, M.; Garcia, A.R.; Holloway, I.W.; Chamberlain, P. Inter-Organizational Collaboration in the Implementation of Evidence-Based Practices Among Public Agencies Serving Abused and Neglected Youth. Adm. Policy Ment. Health Ment. Health Serv. Res. 2014, 41, 74-85. [CrossRef] [PubMed]

39. Flodgren, G.; Deane, K.; Dickinson, H.O.; Kirk, S.; Alberti, H.; Beyer, F.R.; Brown, J.G.; Penney, T.L.; Summerbell, C.D.; Eccles, M.P. Interventions to Change the Behaviour of Health Professionals and the Organisation of Care to Promote Weight Reduction in Overweight and Obese Adults. Cochrane Database Syst. Rev. 2010, 3, CD000984. [CrossRef] [PubMed]

40. Shin, H.-S.; Valente, T.W.; Riggs, N.R.; Huh, J.; Spruijt-Metz, D.; Chou, C.-P.; Pentz, M.A. The Interaction of Social Networks and Child Obesity Prevention Program Effects: The Pathways Trial. Obesity 2014, 22, 1520-1526. [CrossRef] [PubMed]

41. Bess, K.D. Reframing Coalitions as Systems Interventions: A Network Study Exploring the Contribution of a Youth Violence Prevention Coalition to Broader System Capacity. Am. J. Community Psychol. 2015, 55, 381-395. [CrossRef]

42. Godart, F.C.; Claes, K. Semantic Networks and the Market Interface: Lessons from Luxury Watchmaking. In Research in the Sociology of Organizations; Groenewegen, P., Ferguson, J.E., Moser, C., Mohr, J.W., Borgatti, S.P., Eds.; Emerald Publishing Limited: Bingley, UK, 2017; Volume 53, pp. 113-141. ISBN 978-1-78714-434-7.

43. Galea, S.; Ettman, C.K.; Vlahov, D. Urban Health; Oxford University Press: Oxford, UK, 2019; ISBN 978-0-19-091586-5.

44. Lowndes, V.; Skelcher, C. The Dynamics of Multi-Organizational Partnerships: An Analysis of Changing Modes of Governance. Public Adm. 1998, 76, 313-333. [CrossRef]

45. Mcquaid, R.W. Theory of Organizational Partnerships: Partnership Advantages, Disadvantages and Success Factors. Available online: https:/ / dspace.stir.ac.uk/handle/1893/16959\#.YTBoYd8RVPZ (accessed on 29 December 2019).

46. Le Feuvre, M.; Medway, D.; Warnaby, G.; Ward, K.; Goatman, A. Understanding Stakeholder Interactions in Urban Partnerships. Cities 2016, 52, 55-65. [CrossRef]

47. Matous, P.; Wang, P. External Exposure, Boundary-Spanning, and Opinion Leadership in Remote Communities: A Network Experiment. Soc. Netw. 2019, 56, 10-22. [CrossRef] 
48. Luke, D.A. Getting the Big Picture in Community Science: Methods That Capture Context. Am. J. Community Psychol. 2005, 35, 185. [CrossRef]

49. Kothari, A.; Sibbald, S.L.; Wathen, C.N. Evaluation of Partnerships in a Transnational Family Violence Prevention Network Using an Integrated Knowledge Translation and Exchange Model: A Mixed Methods Study. Health Res. Policy Syst. 2014, 12, 25. [CrossRef]

50. Shearer, J.C.; Dion, M.; Lavis, J.N. Exchanging and Using Research Evidence in Health Policy Networks: A Statistical Network Analysis. Implement. Sci. 2014, 9, 126. [CrossRef] [PubMed]

51. Russell, J.L.; Meredith, J.; Childs, J.; Stein, M.K.; Prine, D.W. Designing Inter-Organizational Networks to Implement Education Reform: An Analysis of State Race to the Top Applications. Educ. Eval. Policy Anal. 2015, 37, 92-112. [CrossRef]

52. Holmes, B.J.; Best, A.; Davies, H.; Hunter, D.; Kelly, M.P.; Marshall, M.; Rycroft-Malone, J. Mobilising Knowledge in Complex Health Systems: A Call to Action. Evid. Policy 2017, 13, 539-560. [CrossRef]

53. Lawlor, J.A.; Neal, Z.P. Networked Community Change: Understanding Community Systems Change through the Lens of Social Network Analysis. Am. J. Community Psychol. 2016, 57, 426-436. [CrossRef] [PubMed]

54. Feinberg, M.E.; Riggs, N.R.; Greenberg, M.T. Social Networks and Community Prevention Coalitions. J. Prim. Prev. 2005, 26, 279-298. [CrossRef]

55. Foth, M. Network Action Research. Action Res. 2006, 4, 205-226. [CrossRef]

56. Burns, D. Systemic Action Research: A Strategy for Whole System Change; Policy Press: Bristol, UK, 2007; ISBN 978-1-86134-737-4.

57. Morrison, E. Strategic Doing for Community Development. Available online: https://www.taylorfrancis.com/ (accessed on 21 October 2019).

58. Arnold, G. The Impact of Social Ties on Coalition Strength and Effectiveness: The Case of the Battered Women's Movement in St Louis. Soc. Mov. Stud. 2011, 10, 131-150. [CrossRef]

59. Provan, K.G.; Nakama, L.; Veazie, M.A.; Teufel-Shone, N.I.; Huddleston, C. Building Community Capacity Around Chronic Disease Services through a Collaborative Interorganizational Network. Health Educ. Behav. 2003, 30, 646-662. [CrossRef] [PubMed]

60. Snijders, T.A.B. The Degree Variance: An Index of Graph Heterogeneity. Soc. Netw. 1981, 3, 163-174. [CrossRef]

61. Burt, R.S. A Note on Social Capital and Network Content. Soc. Netw. 1997, 19, 355-373. [CrossRef]

62. Baerveldt, C.; Snijders, T. Influences on and from the Segmentation of Networks: Hypotheses and Tests. Soc. Netw. 1994, 16, 213-232. [CrossRef]

63. Belone, L.; Lucero, J.E.; Duran, B.; Tafoya, G.; Baker, E.A.; Chan, D.; Chang, C.; Greene-Moton, E.; Kelley, M.A.; Wallerstein, N Community-Based Participatory Research Conceptual Model: Community Partner Consultation and Face Validity. Qual. Health Res. 2016, 26, 117-135. [CrossRef]

64. Hicks, S.; Duran, B.; Wallerstein, N.; Avila, M.; Belone, L.; Lucero, J.; Magarati, M.; Mainer, E.; Martin, D.; Muhammad, M.; et al. Evaluating Community-Based Participatory Research to Improve Community-Partnered Science and Community Health. Prog. Community Health Partnersh. Res. Educ. Action 2012, 6, 289-299. [CrossRef] [PubMed]

65. Butterfoss, F.D.; Goodman, R.M.; Wandersman, A. Community Coalitions for Prevention and Health Promotion. Health Educ. Res. 1993, 8, 315-330. [CrossRef]

66. Kumpfer, K.L.; Turner, C.; Hopkins, R.; Librett, J. Leadership and Team Effectiveness in Community Coalitions for the Prevention of Alcohol and Other Drug Abuse. Health Educ. Res. 1993, 8, 359-374. [CrossRef]

67. Foster-Fishman, P.G.; Berkowitz, S.L.; Lounsbury, D.W.; Jacobson, S.; Allen, N.A. Building Collaborative Capacity in Community Coalitions: A Review and Integrative Framework. Am. J. Community Psychol. 2001, 29, 241-261. [CrossRef]

68. McGlashan, J.; Nichols, M.; Korn, A.; Millar, L.; Marks, J.; Sanigorski, A.; Pachucki, M.; Swinburn, B.; Allender, S.; Economos, C. Social Network Analysis of Stakeholder Networks from Two Community-Based Obesity Prevention Interventions. PLoS ONE 2018, 13, e0196211. [CrossRef]

69. Korn, A.R.; Hammond, R.A.; Hennessy, E.; Must, A.; Pachucki, M.C.; Economos, C.D. Evolution of a Coalition Network during a Whole-of-Community Intervention to Prevent Early Childhood Obesity. Child. Obes. Print 2021, 17, 379-390. [CrossRef]

70. Allender, S.; Brown, A.D.; Bolton, K.A.; Fraser, P.; Lowe, J.; Hovmand, P. Translating Systems Thinking into Practice for Community Action on Childhood Obesity. Obes Rev. 2019, 20 (Suppl. S2), 179-184. [CrossRef]

71. Torrence, W.A.; Yeary, K.H.K.; Stewart, C.; Mehta, P.; Duke, K.; Greer-Williams, N.; Guidry, J.J.; Erwin, D.; Greene, P.; HenryTillman, R.S. Evaluating Coalition Capacity to Strengthen Community-Academic Partnerships Addressing Cancer Disparities. J. Cancer Educ. 2011, 26, 658-663. [CrossRef] [PubMed]

72. U.S. Census Bureau 2017-2019 American Community Survey 3-Year Public Use Microdata Samples. 2019. Available online: https:/ / www.census.gov/programs-surveys/acs/microdata.html (accessed on 21 July 2021).

73. Korn, A.R.; Hennessy, E.; Hammond, R.A.; Allender, S.; Gillman, M.W.; Kasman, M.; McGlashan, J.; Millar, L.; Owen, B.; Pachucki, M.C.; et al. Development and Testing of a Novel Survey to Assess Stakeholder-Driven Community Diffusion of Childhood Obesity Prevention Efforts. BMC Public Health 2018, 18, 681. [CrossRef]

74. Adams, J. Gathering Social Network Data; Sage Publications: Los Angeles, CA, USA, 2019.

75. Hunter, R.F.; McAneney, H.; Davis, M.; Tully, M.A.; Valente, T.W.; Kee, F. "Hidden" Social Networks in Behavior Change Interventions. Am. J. Public Health 2015, 105, 513-516. [CrossRef] [PubMed]

76. Valente, T.W. Network Interventions. Science 2012, 337, 49-53. [CrossRef] [PubMed] 
77. Evans, S.D.; Rosen, A.D.; Kesten, S.M.; Moore, W. Miami Thrives: Weaving a Poverty Reduction Coalition. Am. J. Community Psychol. 2014, 53, 357-368. [CrossRef]

78. Bess, K.D.; Speer, P.W.; Perkins, D.D. Ecological Contexts in the Development of Coalitions for Youth Violence Prevention: An Organizational Network Analysis. Health Educ. Behav. 2012, 39, 526-537. [CrossRef] [PubMed]

79. Shapiro, V.B.; Oesterle, S.; Hawkins, J.D. Relating Coalition Capacity to the Adoption of Science-Based Prevention in Communities: Evidence from a Randomized Trial of Communities That Care. Am. J. Community Psychol. 2015, 55, 1-12. [CrossRef]

80. Valente, T.W.; Fujimoto, K.; Palmer, P.; Tanjasiri, S.P. A Network Assessment of Community-Based Participatory Research: Linking Communities and Universities to Reduce Cancer Disparities. Am. J. Public Health 2010, 100, 1319-1325. [CrossRef]

81. Hunter, R.F.; de la Haye, K.; Murray, J.M.; Badham, J.; Valente, T.W.; Clarke, M.; Kee, F. Social Network Interventions for Health Behaviours and Outcomes: A Systematic Review and Meta-Analysis. PLoS Med. 2019, 16, e1002890. [CrossRef] [PubMed]

82. de Groot, F.P.; Robertson, N.M.; Swinburn, B.A.; de Silva-Sanigorski, A.M. Increasing Community Capacity to Prevent Childhood Obesity: Challenges, Lessons Learned and Results from the Romp \& Chomp Intervention. BMC Public Health 2010, $10,522$. [CrossRef] 